$30 \mathrm{~min}$, the cells were washed 5 times with $200 \mu \mathrm{l}$ PBS $+0.1 \%$ TritonX-100, resuspended in $6 \mu \mathrm{l}$ mounting media and placed on a slide. The sensitivities of wild-type, cof $1-5$ and $c o f 1-22$ cells to lat-A were examined in a halo-assay ${ }^{11}$ in which filters spotted with Lat-A were deposited on lawns of yeast and the diameter of zones of growth inhibition measured. For actin-patch movement studies, the COF1 and cof1-22 strains were transformed with a plasmid carrying GFP linked to Abp1 (ref. 19). Cells from such transformants were grown at $20^{\circ} \mathrm{C}$ to an $A_{600}$ of $\sim 0.4$, and movement of actin patches was followed with Zeiss Axiovert 100TV microscope. Images from about 400 patches in 5 unbudded cells from each strain were collected using a Princeton Instruments ST-138 camera/controller with a Kodak KAF1400 chip (each pixel is $0.069 \mu \mathrm{m} \times 0.069 \mu \mathrm{m})$. Frames from the cells were recorded at intervals of 0.95 to $1.25 \mathrm{~s}$ and the data analysed using the Animate program (written by A. Mallavarapu). The maximum speeds observed in our study $\left(0.75 \mu \mathrm{m} \mathrm{s}^{-1}\right)$ are approximately twofold slower than the maximum speeds previously reported $^{18}$. This might result from differences in yeast strain backgrounds or the differences in the time resolution of image acquisition (the camera system in ref. 18 recorded frames with 0.2 -s intervals compared to $\sim 1$-s intervals in this study).

In vitro depolymerization assay. The $C O F 1$ yeast cofilin gene was amplified by PCR, subcloned into pGEX2T vector (Pharmacia), and expressed in Escherichia coli JM109 cells as a glutathione $S$-transferase (GST) fusion protein. Site-directed mutations were introduced to pGEX2T-COF1 plasmid by oligonucleotide-based mutagenesis (Transformer, Clontech). Fusion proteins were purified by glutathione-agarose affinity chromatography ${ }^{29}$. All constructs made by PCR were sequenced to exclude the possibility of undesired mutations. Cofilin was cleaved from GST by thrombin and purified by gel-filtration (Superdex-75, Pharmacia). Yeast actin was purified as described ${ }^{30}$ and polymerized in F-buffer comprising (in $\mathrm{mM}$ ) 20 Tris, $\mathrm{pH} 7.5,100 \mathrm{KCl}, 2 \mathrm{MgCl}_{2}, 0.7$ ATP, 0.2 DTT, $0.2 \mathrm{CaCl}_{2}$, at a final concentration of $5 \mu \mathrm{M}$. For the depolymerization assay, $\mathrm{F}$-actin and cofilin were mixed in a cuvette to final concentrations of $0.5 \mu \mathrm{M}$, and the depolymerization of F-actin was followed by decrease in light scattering at $400 \mathrm{~nm}$.

Received 13 March; accepted 21 April 1997.

. Moon, A. \& Drubin, D. G. The ADF-cofilin proteins: Stimulus responsive modulators of actin dynamics. Mol. Biol. Cell 6, 1423-1431 (1995).

2. Bamburg, J. R., Harris, H. E. \& Weeds, A. G. Partial purification and characterization of an actin depolymerizing factor from brain. FEBS Lett. 121, 178-182 (1990).

Yonezawa, N., Nishida, E. \& Sakai, H. pH control of actin polymerization by cofilin. J. Biol. Chem. 260 14410-14412 (1985)

4. Hawkins, M., Pope, B., Maciver, S. K. \& Weeds, A. G. Human actin depolymerizing factor mediates a pH-sensitive destruction of actin filaments. Biochemistry 32, 9985-9993 (1993).

. Hayden, S. M., Miller, P. S., Brauweiler, A. \& Bamburg, J. R. Analysis of the interactions of actin depolymerizing factor with G- and F-actin. Biochemistry 32, 9994-10004 (1993).

Moon, A. L., Janmey, P. A., Louie, K. A. \& Drubin, D. G. Cofilin is an essential component of the yeast cortical cytoskeleton. J. Cell Biol. 120, 421-435 (1993).

. Gunsalus, K. C. et al. Mutations in twinstar, a Drosophila gene encoding a cofilin-ADF homologue, result in defects in centrosome migration and cytokinesis. J. Cell Biol. 131, 1243-1259 (1995).

8. McKim, K. S., Matheson, C., Marra, M. A., Wakarchuk, M. F. \& Baillie, D. L. The Caenorhabditi elegans unc-60 gene encodes protein homologous to a family of actin binding proteins. Mol. Gen Genet. 242, 346-357 (1994)

9. Mulholland, J. et al. Ultrastructure of the yeast actin cytoskeleton and its association with the plasma membrane. J. Cell Biol. 125, 381-391 (1994).

10. Coue, M., Brenner, S. L., Spector, I. \& Korn, E. D. Inhibition of actin polymerization by Latranculin-A. FEBS Lett. 213, 316-318 (1987).

11. Ayscough, K. R. et al. High rates of actin filament turnover in budding yeast and roles for actin in establishment and maintenance of cell polarity revealed using the actin inhibitor Latranculin-A. J. Cell Biol. 137, 399-416 (1997).

12. Holtzman, D. A., Yang, S. \& Drubin, D. G. Synthetic-lethal interactions identify two novel genes, SLA and SLA2, that control membrane cytoskeleton assembly in Saccharomyces cerevisiae. J. Cell Biol. 122, 635-644 (1993)

13. Kubler, E. \& Riezman, H. Actin and fimbrin are required for the internalization step of endocytosis in yeast. $E M B O J .12,2855-2862$ (1993).

14. Freeman, N. L., Chen, Z., Horenstein, J., Weber, A. \& Field, J. An actin monomer binding activity localizes to the carboxyl half of the Saccharomyces cerevisiae cyclase associated protein. J. Biol. Chem. 270, 5680-5685 (1995)

15. Geli, M. I. \& Riezman, H. Role of type I myosins in receptor-mediated endocytosis in yeast. Science 272, 533-535 (1996)

16. Goodson, H. V. et al. Synthetic lethality screen identifies a novel yeast myosin I gene (MYO5) - Myosin I proteins are required for polarization of the actin cytoskeleton. J. Cell Biol. 133, 1277-1291 (1996).

17. Benedetti, H., Raths, S., Crauzas, F. \& Riezman, H. The END3 gene encodes a protein that is required for the internalization step of endocytosis and for actin ctyoskeleton organization in yeast. Mol. Biol. Cell 5, 1023-1037 (1994).

18. Waddle, J. A., Karpova, T. S., Waterston, R. H. \& Cooper, J. A. Movement of cortical actin patches in yeast. J. Cell Biol. 132, 861-870 (1996).

19. Doyle, T. \& Botstein, D. Movement of yeast cortical actin cytoskeleton visualized in vivo. Proc. Nat Acad Sci. USA 93, 3886-3891 (1996).

20. Welch, M. D., Mallavarapu, A., Rosenblatt, J. \& Mitchison, T. J. Actin dynamics in vivo. Opin. Cell Biol 9, 54-61 (1997).
1. Rosenblatt, J., Agnew, B. J., Abe, H., Bamburg, J. R. \& Mitchison, T. J. Xenopus actin depolymerizing factor/cofilin XAC is responsible for the turnover of actin filaments in Listeria monocytogenes tails. J. Cell Biol. 136, 1323-1332 (1997).

22. Carlier, M. et al. Actin depolymerizing factor (ADF/cofilin) uses ATP hydrolysis to enhance actin dynamics. J. Cell Biol. 136, 1307-1322 (1997).

23. Yonezawa, N., Nishida, E., Iida, K., Yahara, I. \& Sakai, H. Inhibition of the interactions of cofilin, destrin and deoxyribonuclease-I with actin by phosphoinositides. J. Biol. Chem. 265, 8382-8386 (1990).

24. Agnew, B. J., Minamide, L. S. \& Bamburg, J. R. Reactivation of phosphorylated actin depolymerizing factor and identification of the regulatory site. J. Biol. Chem. 270, 17582-17585 (1995).

25. Abe, H., Obinata, T., Minamide, L. S. \& Bamburg, J. R. Xenopus laevis actin-depolymerizing factor/ cofilin: A phosphorylation-regulated protein essential for development. J. Cell Biol. 132, 871-885 (1996). 26. Adams, A. E. M., Botstein, D. \& Drubin, D. G. Requirement of yeast fimbrin for actin organization and morphogenesis in vivo. Nature 354, 404-408 (1991).

27. Lila, T. \& Drubin, D. G. Evidence for physical and functional interactions among two Saccharyomyces cerevisiae $\mathrm{SH} 3$ domain proteins, an adenylyl cyclase-associated protein and the actin cytoskeleton. Mol. Biol. Cell 8, 367-385 (1997).

28. Dulic, V. et al. Yeast endocytosis assays. Methods Enzymol. 194, 697-710 (1991).

29. Ausubel, F. M. et al. Current Protocols in Molecular Biology (John Wiley, New York, 1990).

30. Buzan, J. M. \& Frieden, C. Yeast actin: Polymerization kinetic studies of wild-type and a poorly polymerizing mutant. Proc. Natl Acad. Sci. USA 93, 91-95 (1996).

Acknowledgements. We thank K. Ayscough for the Lat-A disassembly procedure; L. Belmont, B. Goode and K. Kozminski for comments on the manuscript; and A. Mallavarapu and T. Mitchison for help in recording patch movements. This work was supported by long-term fellowships from the European Molecular Biology Organization and Human Frontier Science Program (to P.L.) and by grants from the NIH and American Cancer Society (to D.G.D.).

Correspondence and requests for materials should be addressed to D.G.D. (e-mail: drubin@mendel. berkeley.edu).

\section{Mutations increasing autoinhibition inactivate tumour suppressors Smad2 and Smad4}

\section{Akiko Hata*, Roger S. Lo*, David Wotton*, Giorgio Lagna $+\&$ Joan Massagué ${ }^{\star}$}

* Cell Biology Program and Howard Hughes Medical Institute, Memorial SloanKettering Cancer Center, $\dagger$ Laboratory of Molecular Embryology,

The Rockefeller University, New York, New York 10021, USA

Smad2 and Smad4 are related tumour-suppressor proteins ${ }^{1,2}$, which, when stimulated by the growth factor TGF- $\beta$, form a complex to inhibit growth ${ }^{3}$. The effector function of Smad2 and Smad4 is located in the conserved carboxy-terminal domain (C domain) of these proteins and is inhibited by the presence of their amino-terminal domains ( $\mathrm{N}$ domain $)^{4,5}$. This inhibitory function of the $\mathrm{N}$ domain is shown here to involve an interaction with the $\mathrm{C}$ domain that prevents the association of Smad2 with Smad4. This inhibitory function is increased in tumour-derived forms of Smad 2 and 4 that carry a missense mutation in a conserved $\mathrm{N}$ domain arginine residue. The mutant $\mathrm{N}$ domains have an increased affinity for their respective $C$ domains, inhibit the Smad2-Smad4 interaction, and prevent TGFß-induced Smad2Smad4 association and signalling. Whereas mutations in the $\mathrm{C}$ domain disrupt the effector function of the Smad proteins, Ndomain arginine mutations inhibit SMAD signalling through a gain of autoinhibitory function. Gain of autoinhibitory function is a new mechanism for inactivating tumour suppressors.

SMAD proteins are central to signalling by the TGF- $\beta$ family of growth factors ${ }^{6}$. An effector function of the $\mathrm{C}$ domain and an inhibitory function of the $\mathrm{N}$ domain of Smad proteins were discovered during studies on the mesoderm-inducing activity of Smad2 in Xenopus embryo explants ${ }^{5}$ and on the transcriptional activity of various Smad proteins in mammalian cells ${ }^{4}$. SMAD proteins exist as homo-oligomers that form functional heterooligomeric complexes in response to TGF- $\beta$ and related factors ${ }^{3}$. These complexes are formed by association of a pathway-restricted SMAD with the shared SMAD, Smad4 (also known as DPC4 or deleted in pancreatic carcinoma 4). Thus Smad1 associates with Smad4 in response to stimulation by bone morphogenic protein 
$(\mathrm{BMP})^{3}$, whereas Smad2, or its close isoform Smad3, associates with Smad4 in response to stimulation by TGF- $\beta$ or activin ${ }^{3,7}$. These associations occur on receptor-mediated phosphorylation of the pathway-restricted $\mathrm{SMADs}^{3,7-10}$.

To investigate the domains involved in these interactions, we tested various Smad4 fragments as baits either against Smad4, to detect homo-oligomeric interaction, or against Smad2, to detect hetero-oligomeric interaction, in a yeast two-hybrid system. Fulllength Smad4 interacted with the $\mathrm{N}$ domain/linker region as a whole but not with those two regions when they were separately expressed (Fig. 1a). Full-length Smad4 interacted with its isolated C domain (Fig. 1a). These results indicate that both the $\mathrm{C}$ domain and the $\mathrm{N}$ domain/linker region can contribute to the homo-oligomeric interaction in Smad4 (Fig. 1a). Furthermore, the isolated C domain of Smad4 interacted with itself (data not shown), which was unexpected ${ }^{11}$. The homo-oligomeric interaction pattern of
Smad4 in yeast is consistent with a contribution of all three regions to the homo-oligomeric interaction, with the $\mathrm{C}$ domain providing the strongest. The crystal structure of the Smad4 C domain has revealed that this domain forms a homotrimer whose interfaces are the targets of cancer mutations ${ }^{12}$. Smad2 gave a similar, but not identical, pattern of homo-oligomeric interactions in yeast (Fig. 1a).

The Smad2-Smad4 complex was detectable in yeast and was particularly sensitive to deletions in the $\mathrm{C}$ domain (Fig. 1a). Furthermore, Smad2 and Smad4 (Fig. 1a) or their isolated C domains (data not shown) interacted with the other's isolated $\mathrm{C}$ domain. In contrast to its dependence on TGF- $\beta$ stimulation in mammalian cells ${ }^{3}$, the Smad2-Smad4 interaction occurred spontaneously in yeast, perhaps as a result of Smad phosphorylation by yeast kinases. These interactions were also analysed in mammalian cells by transfection of Smad 2 and Smad4 fragments tagged with a Flag or HA epitope. The isolated C domains of Smad 2 and 4 each
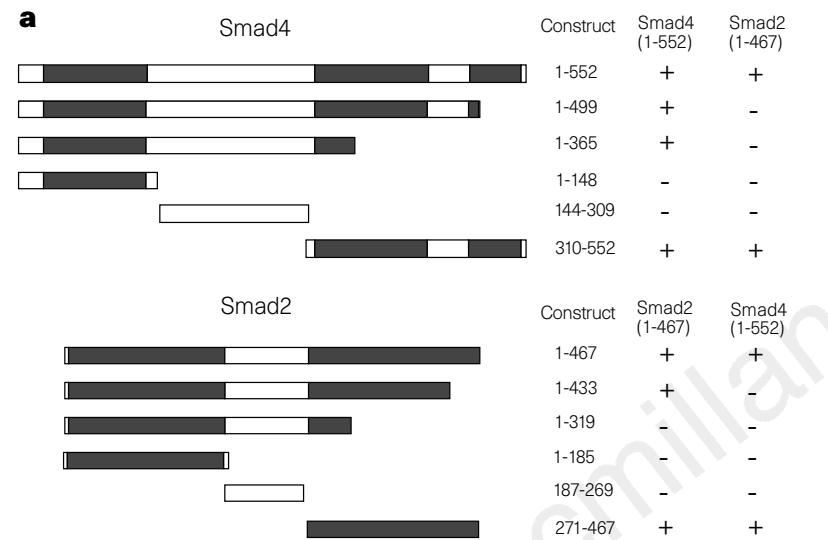
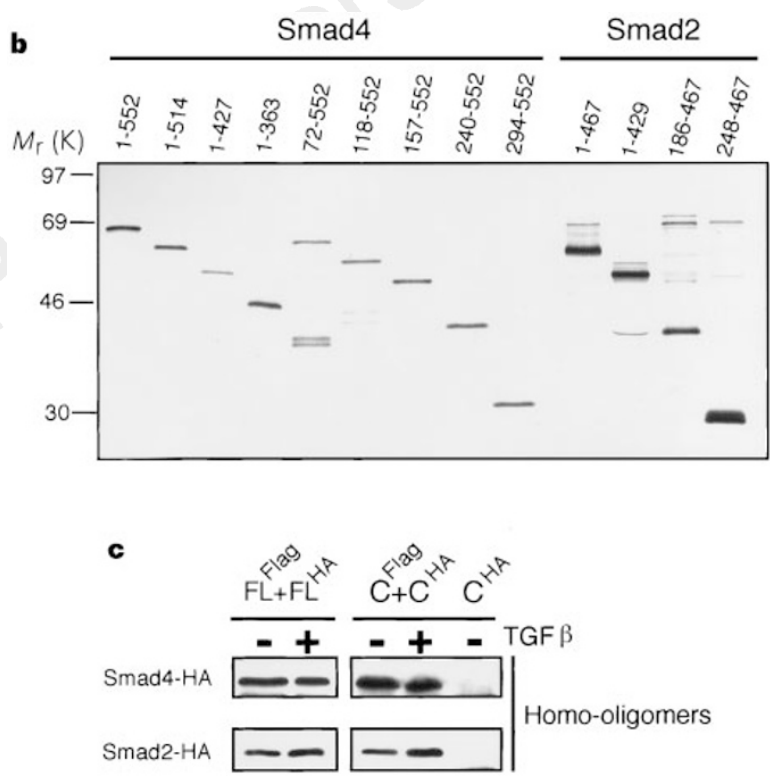

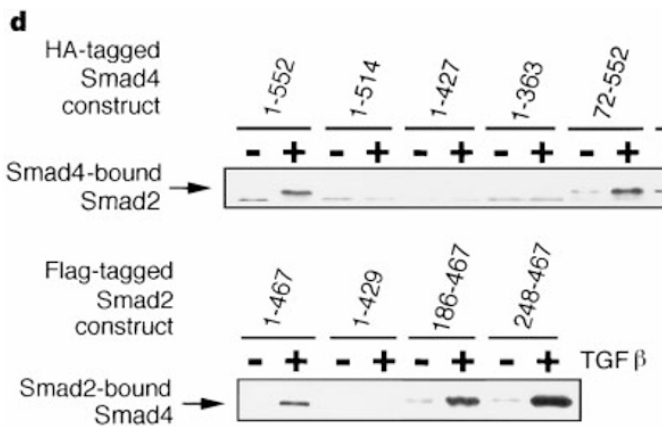

e

$\begin{array}{ccc}\begin{array}{c}\text { N domain } \\ \begin{array}{c}\text { Repressor of } \\ \text { hetero-oligomer }\end{array}\end{array} & \text { Linker } & \text { C domain } \\ \text { Hetero- } \\ \text { oligomerization }\end{array}$

Figure 1 Analysis of Smad4 and Smad2 domain interactions. a, Smad4 and Smad2 interactions with themselves and each other in a yeast two-hybrid system. The indicated portions of Smad4 or Smad2 were tested for interaction with fulllength or $\mathrm{C}$ domains of Smad2 or Smad4 fused to the LexA DNA-binding domain. b. Expression of HA-tagged Smad4 constructs and Flag-tagged Smad2 constructs was determined by epitope-tag immunoprecipitation from ${ }^{35} \mathrm{~S}$ methionine-labelled cells. c, Homo-oligomerization of Smad4 or Smad2 C domains. COS cells were transiently transfected with full-length (FL) Smad4 or Smad2 or their $\mathrm{C}$ domains (C) (Smad4 amino acids 294-552; Smad2 amino acids
248-467). Versions of the same protein tagged at the amino terminus with the Flag epitope or at the carboxy terminus with the HA epitope were co-transfected. Some cultures were incubated with TGF- $\beta$ for $1 \mathrm{~h}$ before lysis. Homooligomerization was analysed by anti-HA immunoblotting of anti-Flag immunoprecipitates. d, Hetero-oligomerization of cotransfected HA-tagged Smad4 and Flag-tagged Smad2 deletion constructs. Smad2-Smad4 interaction was analysed by anti-Flag immunoblotting of anti-HA immunoprecipitates (top) or anti-HA immunoblotting of anti-Flag immunoprecipitates (bottom). e, Summary of SMAD domain contributions to Smad2-Smad4 hetero-oligomerization. 
formed homo-oligomers in COS cells, as determined by co-immunoprecipitation of differently tagged constructs (Fig. 1c). In agreement with previous reports ${ }^{3}$, the Smad2-Smad4 interaction in COS cells requires TGF- $\beta$ receptor stimulation (Fig. 1d), whereas the homo-oligomeric interactions do not (Fig. 1c). The $\mathrm{C}$ domains of Smad 2 and Smad 4 were necessary and sufficient for this interaction (Fig. 1d).

Deletion of the $\mathrm{N}$ domain in either Smad2 or Smad4 caused a constitutive association with the full-length version of the other protein, and this association was further enhanced by TGF- $\beta$ action (Fig. 1d). The amount of expression of the Smad2 and Smad4 deletion products was similar to that of the full-length proteins (Fig. 1b), arguing that the constitutive association was not due to higher

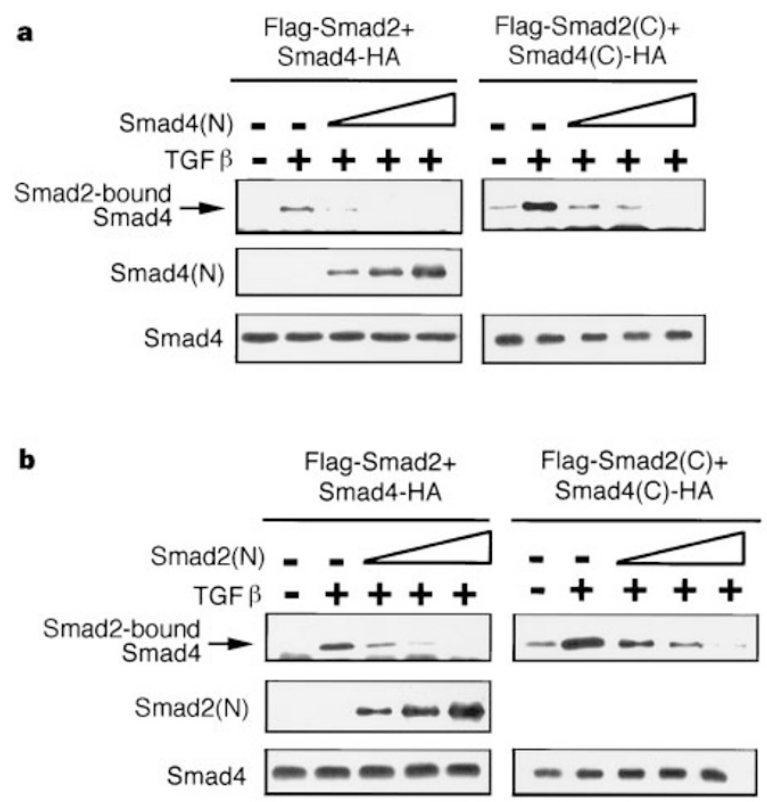

c

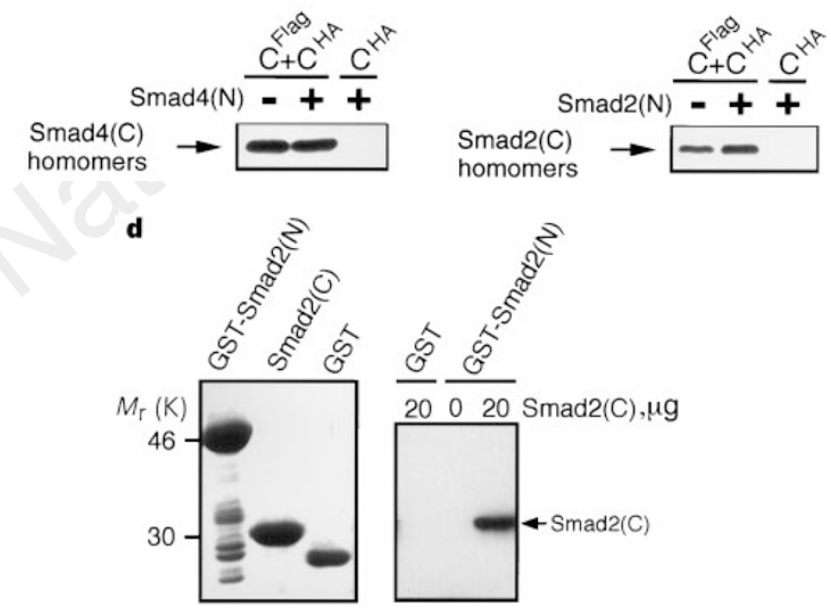

Figure 2 a, b, Inhibition of Smad2-Smad4 interaction by $\mathrm{N}$ domains. Increasing amounts (1,2 and $4 \mu \mathrm{g}$ ) of plasmid encoding the Smad4 $\mathrm{N}$ domain (amino acids 1 154) or the Smad2 N domain (amino acids 1-185) were co-transfected with the indicated full-length or $\mathrm{C}$ domain forms of Smad4 and Smad2. Smad2-Smad4 association was then determined. $\mathrm{N}$ domain and Smad4 expression was monitored by immunoblotting. c, $\mathrm{N}$ domain expression does not affect $\mathrm{C}$ domain homo-oligomerization. Flag-tagged and HA-tagged versions of Smad C domains were co-transfected with the indicated $\mathrm{N}$ domain. $\mathbf{d}$, Specific interaction of the Smad2 N domain with the Smad2 C domain in vitro. Bacterially expressed proteins (Coomassie-blue-stained gel, left) were used to demonstrate Smad2(C) binding to GST-Smad2(N) but not to GST alone (right). expression of the $\mathrm{N}$ domain-deletion products. Thus, the combined results in yeast and COS cells indicate that the Smad2-Smad4 interaction is mediated primarily by the $\mathrm{C}$ domains, requires the integrity of these domains, and is inhibited by the presence of the $\mathrm{N}$ domains (Fig. 1e).

Consistent with this inhibitory function, expression of the Smad4 $\mathrm{N}$ domain (Fig. 2a) or the Smad2 $\mathrm{N}$ domain (Fig. 2b) inhibited the association between full-length as well as the C-domain forms of Smad 2 and Smad4 in COS cells. This effect is specific because the overexpression of $\mathrm{N}$ domains does not inhibit homo-oligomerization of the $\mathrm{C}$ domains (Fig. 2c) or the expression of cotransfected $\mathrm{C}$ domains (data not shown). In yeast, the isolated $\mathrm{N}$ domains of Smad 2 and 4 interacted weakly with their respective $C$ domains (data not shown) and not at all with the full-length proteins (Fig. 1a). However, a fusion protein of glutathione-S-transferase (GST) with the Smad $2 \mathrm{~N}$ domain specifically bound the Smad $2 \mathrm{C}$ domain when tested as recombinant proteins in vitro (Fig. 2d). Furthermore, the Smad 2 and $4 \mathrm{~N}$ domains interacted with their corresponding $\mathrm{C}$ domains in COS cells (Fig. 5c). The more efficient interaction of the Smad $\mathrm{N}$ and $\mathrm{C}$ domains in COS cells may require a post-translational modification or an accessory factor.

As the formation of Smad2-Smad4 complexes requires Smad2 phosphorylation $^{10}$ at C-terminal serines ${ }^{9,10}$, we investigated how this
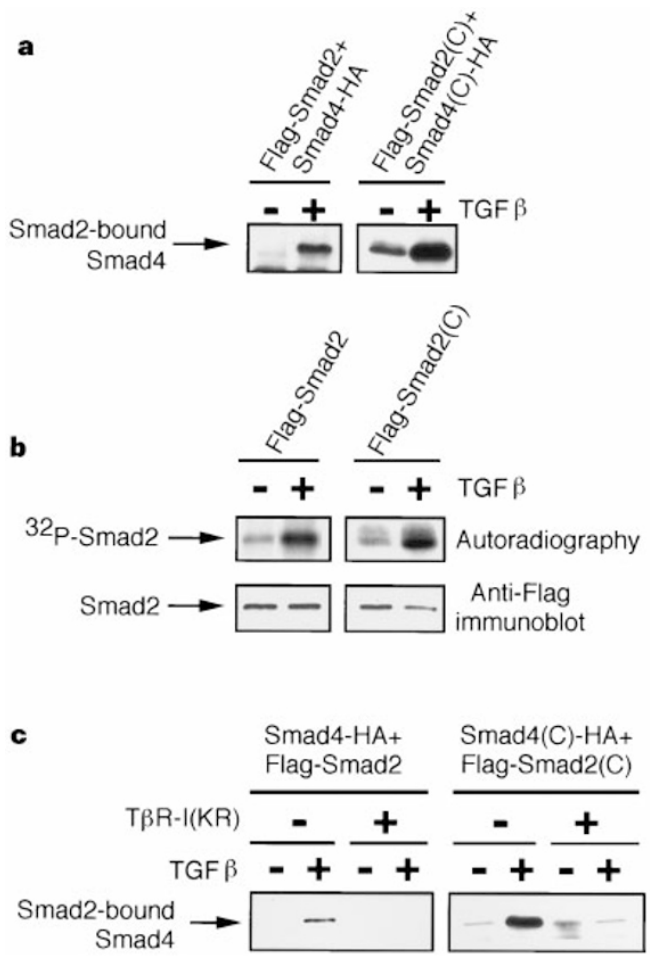

Figure 3 Effect of $\mathrm{N}$ domain deletion and agonist-induced phosphorylation on Smad2-Smad4 interaction. a, Constitutive association of the isolated $\mathrm{C}$ domains of Smad4 and Smad2, and further stimulation by TGF- $\beta$. The indicated full-length or $\mathrm{C}$ domain forms of Smad2 or Smad4 were cotransfected into COS cells. Cultures were stimulated with TGF- $\beta$, and Smad2-Smad4 interactions were analysed. $\mathbf{b}$, Smad2 C domain phosphorylation in response to TGF- $\beta$. Constructs were transiently co-transfected with T $\beta$ R-I into R-1B/L17 cells. Transfectants were labelled with ${ }^{32} \mathrm{P}$-orthophosphate, stimulated with TGF- $\beta$ for $20 \mathrm{~min}$, and immunoprecipitated with anti-Flag antibody. c, The constitutive interaction of Smad4 and Smad2 C domains is independent of TGF- $\beta$-receptor-mediated phosphorylation. Smad2-Smad4 (full-length or C domain) complex formation was analysed in the presence or absence of a cotransfected dominant negative T $\beta$ R-I construct $(T \beta R-I(K R))$. 
process related to the inhibitory effect of the $\mathrm{N}$ domain. The Smad2 and Smad4 C domains spontaneously associated with each other and this association was further stimulated by TGF- $\beta$ (Fig. 3a). The phosphorylation of the Smad2 C domain in response to TGF- $\beta$ was comparable to that of full-length Smad2 (Fig. 3b). Co-transfection of a kinase-inactive, dominant-negative TGF- $\beta$ type-I receptor $[\mathrm{T} \beta \mathrm{R}-\mathrm{I}(\mathrm{K} 232 \mathrm{R})]^{13}$ abolished the TGF- $\beta$-stimulated association of Smad 2 and Smad $4 \mathrm{C}$ domains but not their constitutive association (Fig. 3c). Thus the Smad2-Smad4 interaction is stimulated not only by phosphorylation of the Smad $2 \mathrm{C}$ domain ${ }^{10}$ but also by removal of the $\mathrm{N}$ domains.

We next investigated Smad2 and Smad4 products containing Ndomain mutations that had been identified in human cancers ${ }^{2,14}$. Smad 4 mutations have been found in cancers of the pancreas, colon, oesophagus, breast, ovary, and head and $\operatorname{neck}^{1,14-17}$; Smad2 mutations have been found in colon and head and neck cancers ${ }^{2,18,19}$. Most of the missense mutations reported so far are in the $\mathrm{C}$ domains of Smad 2 or 4 . The three-dimensional structure of the Smad4 C domain predicts that some of these mutations destabilize the core

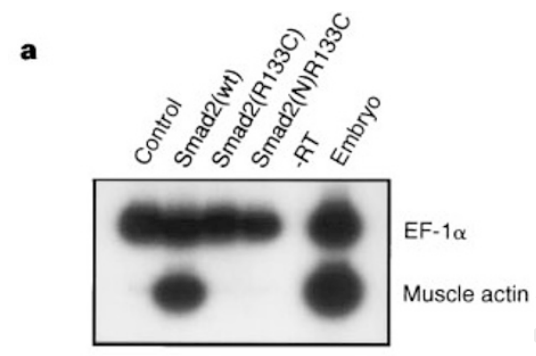

b
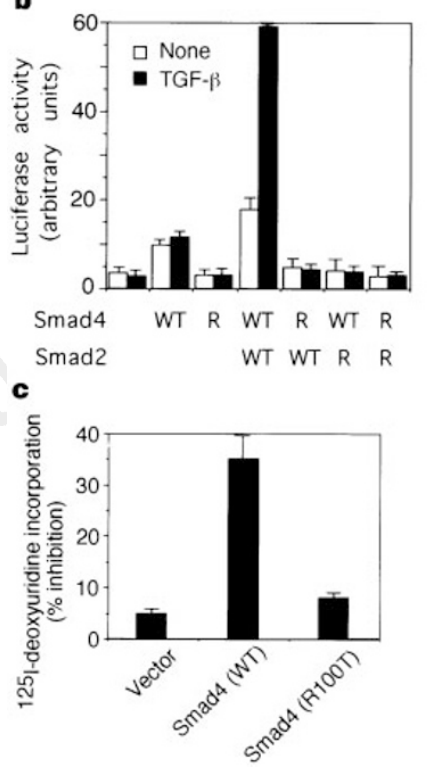

Figure 4 Biological activity of Smad2 and Smad4 containing tumour derived Ndomain mutations. a, Wild-type Smad2 induces the paraxial mesoderm marker muscle actin in Xenopus ectodermal explants, whereas Smad2(R133C) or its $\mathrm{N}$ domain alone (Smad2(N)R133C) are unable to induce it. EF-1 $\alpha$ was used as an internal control. b, Cotransfection of wild-type Smad2 and Smad4 (WT) restores TGF- $\beta$ responsiveness into Smad4-defective MDA-MB468 breast cancer cells, whereas cotransfections including the Smad2(R133C) mutant (R), the Smad4(R100T) mutant (R), or both mutants, do not. The TGF- $\beta$ responsiveness of these cells was determined using the reporter construct 3TP-lux. c, Overexpression of wild-type Smad4 inhibits MDA-MB468 cell proliferation, whereas overexpression of the Smad4(R100T) mutant does not. The proliferation of the cells was determined by measuring iododeoxyuridine incorporation into DNA. Results are the average \pm s.d. of triplicate assays. structure, others disrupt the C-domain homotrimer interface, and others disrupt a putative Smad4-Smad2 interface ${ }^{12}$. Missense mutations have also been identified in the $\mathrm{N}$ domains of Smad2 and Smad4, including a Smad2 Arg133Cys mutation in a colon carcinoma $^{2}$ and a Smad4 Arg100Thr mutation in a pancreatic carcinoma $^{14}$. Arg 133 in Smad2 corresponds to Arg100 in Smad4 (ref. 2), both of which are located in a highly conserved region of the SMAD proteins, suggesting that mutations at this residue are selected in cancer.

We confirmed that these $\mathrm{N}$-domain mutations inactivate the signalling function of Smad2 and Smad4. In the Xenopus embryo, injection of Smad2 transcripts mimics the ability of activin to induce dorsal mesoderm in ectodermal explants ${ }^{5,20}$. The Arg133Cys mutation prevented Smad2 from inducing muscle actin, a paraxial mesoderm marker, in this assay (Fig. 4a). In the human breast carcinoma cell line MDA-MB468, which has a Smad4 homozygous deletion ${ }^{14}$ and is therefore insensitive to TGF- $\beta$ (ref. 3), Smad4 transfection restores TGF- $\beta$ sensitivity; this sensitivity is enhanced by co-transfection of Smad2 (ref. 3). Using the TGF- $\beta$ reporter gene construct 3TP-luciferase ${ }^{13}$, we found that mutation of Arg 133 in Smad2 or Arg100 in Smad4 stopped the co-transfected constructs from restoring TGF- $\beta$ responsiveness in these cells (Fig. 4b). Moreover, Smad4 overexpression inhibits the proliferation of MDA-MB468 cells ${ }^{3}$, which was also disrupted by the Arg100Thr mutation (Fig. 4c).

To determine the basis for the inactivating effect of these $\mathrm{N}$ domain mutations, we transfected mutant Smad 2 and Smad 4 into COS cells and investigated their expression and interactions. Expression of both mutants was similar to wild type (Fig. 5a), as was their ability to form homo-oligomers (Fig. 5b). But both mutants failed to form Smad2-Smad4 complexes in response to TGF- $\beta$ (Fig. 5b). As the Smad2-Smad4 interaction is primarily a function of the $\mathrm{C}$ domains and is repressed by the $\mathrm{N}$ domains, we investigated the inhibitory function of the wild-type and mutant $\mathrm{N}$ domains.

When expressed as separate polypeptides in COS cells, the $\mathrm{N}$ domains of Smad2 or Smad4 associate with the corresponding C domain (Fig. 5c). This association is not observed between the $\mathrm{N}$ domain of one SMAD and the C domain of the other (Fig. $5 \mathrm{c}$ ). The Smad2 and Smad4 mutant $\mathrm{N}$ domains interacted with the corresponding $\mathrm{C}$ domains more strongly (18- and 22-fold, respectively) than did the wild-type $\mathrm{N}$ domains (Fig. 5c). As these mutations do not increase expression of the $\mathrm{N}$ domains, this increase in binding probably results from an increase in affinity of the mutant $\mathrm{N}$ domains for the $\mathrm{C}$ domains. Furthermore, the mutant $\mathrm{N}$ domains were more effective than wild-type N domains at inhibiting Smad2Smad4 hetero-oligomerization (Fig. 5d).

To determine the effect of the Smad4 $\mathrm{N}$ domain on signalling by Smad2-Smad4, we tested its effect on the activation by Smad2 and Smad4 of the 3TP-luciferase reporter. In agreement with previous studies ${ }^{3}$, overexpression of Smad 2 and Smad 4 or of their $\mathrm{C}$ domains activated this reporter (Fig. 5e). Co-transfection of the Smad2 or Smad4 N domains significantly inhibited this effect (Fig. 5e). Furthermore, the mutant $\mathrm{N}$ domains were more potent inhibitors than the wild-type $\mathrm{N}$ domains of the Smad2/Smad4mediated response (Fig. 5e). Thus, the binding of a Smad N domain to the corresponding $\mathrm{C}$ domain correlates with inhibition of the Smad2-Smad4 interaction and signalling function. We conclude that the Arg133Cys and Arg100Thr mutations increase the inhibitory function of the Smad2 and Smad4 $\mathrm{N}$ domains and inactivate signalling by Smad2-Smad4. As Smad4 partners other SMAD proteins besides Smad2 (refs 3, 7), the Arg100Thr mutation should disrupt signalling by these proteins as well.

We have shown that the $\mathrm{N}$ domain in SMAD proteins interacts with and represses the effector function of the $\mathrm{C}$ domain, and that certain Smad2 and Smad4 mutations found in human cancer cells inactivate these proteins by augmenting the inhibitory function of 
a

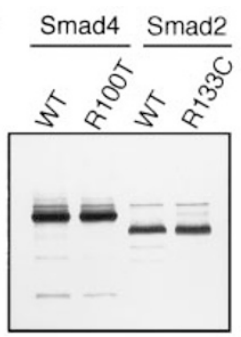

b

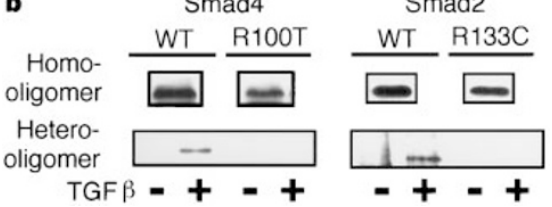

c

Smad4(N) Smad2(N)

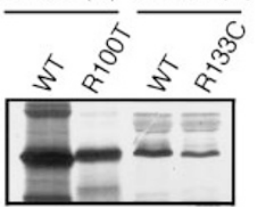

35 S-labelling

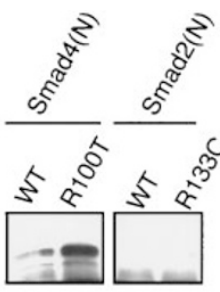

Smad(N)-bound Smad4(C)

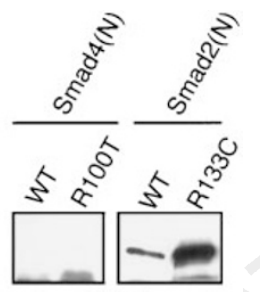

$\operatorname{Smad}(\mathrm{N})$-bound $\mathrm{Smad} 2(\mathrm{C})$
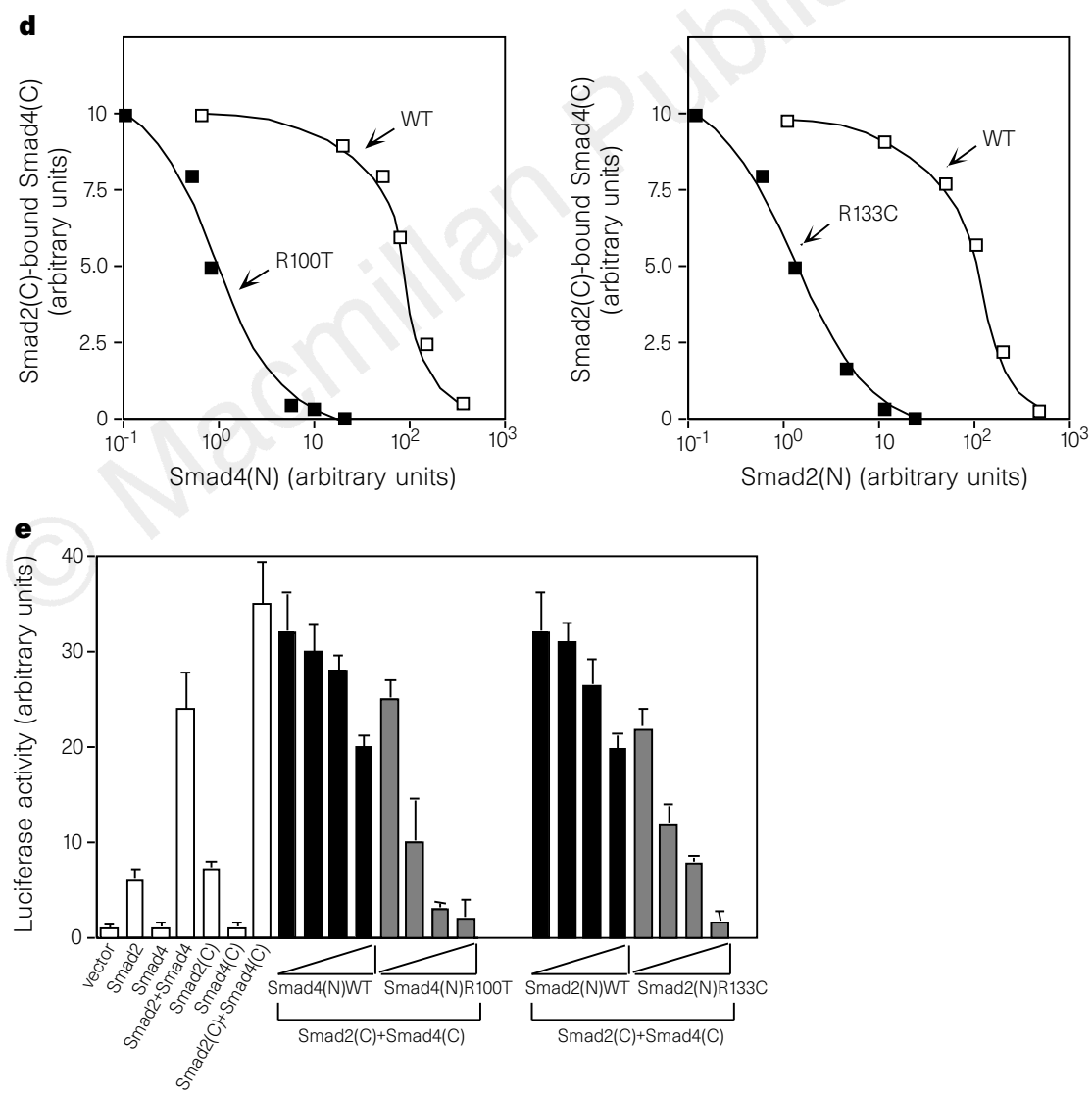

Figure 5 Gain of autoinhibitory function of Smad4 and Smad2 N domain mutants. a, Expression of wild-type and mutant Smads were determined by epitope-tag immunoprecipitation from ${ }^{35} \mathrm{~S}$-methionine-labelled transfected COS cells. b, N domain mutations inhibit Smad2-Smad4 interaction. HA-tagged wild-type or mutant Smad4 was co-transfected with Flag-tagged Smad4 (for homo-oligomeric interaction) or Flag-tagged Smad2 (for hetero-oligomeric interaction) in COS cells. Likewise, Flag-tagged wild-type or mutant (R133C) Smad2 was cotransfected with HA-tagged Smad2 or HA-tagged Smad4. c, N domain interaction with the C domain, and its enhancement by mutation. Flag-tagged $\mathrm{N}$ domains were cotransfected with the HA-tagged $\mathrm{C}$ domains indicated at the bottom. N domain interaction with the $\mathrm{C}$ domain was determined by anti-HA immunoblotting of anti-Flag immunoprecipitates. $\mathrm{N}$ domain expression was monitored by immunoprecipitaiton from ${ }^{35} \mathrm{~S}$-methionine-labelled cells. d, Mutant $\mathrm{N}$ domains inhibit the Smad2-Smad4 interaction more strongly. Increasing amounts of plasmid DNA encoding wild-type or mutant (R100T) Smad4 N domain (left) or wildtype or mutant (R133C) Smad2 N domain (right) were cotransfected with Flagtagged Smad2 C domain and HA-tagged Smad4 C domain. The amounts of Smad4 or Smad2 $\mathrm{N}$ domain protein and Smad2(C)-bound Smad4(C) were determined by immunoblotting, quantified (ImageQuant; Molecular Dynamics) and plotted against each other. e, $\mathrm{N}$ domain inhibition of Smad2-Smad4 signalling. R-1B/L17 cells were transiently transfected with the indicated constructs and 3TP-Iux reporter. Amounts of transfected Smad4 and Smad2 were adjusted $^{3}$ to increase luciferase expression synergistically. Increasing amounts $(1,2,4$ and $6 \mu \mathrm{g})$ of plasmid DNA encoding wild-type or mutant $\mathrm{N}$ domains were cotransfected with a Smad4(C)/Smad2(C) combination. Results (luciferase activity in arbitrary units) are the average \pm s.d. of triplicate assays. 
the $\mathrm{N}$ domain. Other tumour-suppressor mutations, including missense mutations in the $\mathrm{C}$ domains of Smad2 and Smad4, act by disrupting protein stability or effector function ${ }^{12}$. Our findings reveal a mechanism of tumour suppressor inactivation which instead involves a gain of autoinhibitory function. Antagonists of SMAD autoinhibition might be useful in reversing the effects of this type of mutation.

\section{Methods}

Construction of expression vectors. To generate human Smad4 and Smad2 mutations, a fragment of the corresponding $\mathrm{CDNAs}^{1,4}$ was amplified by PCR. The amplified region was subcloned into full-length Smad4 or Smad2 in pCMV5 for transfection into mammalian cells. The regions amplified by PCR and the presence of missence mutations were confirmed by sequencing.

Yeast two-hybrid system. LexA fusions were created in pBTM 116 (ref. 21) and GAD fusions within pGAD424 (Clontech). Interactions were tested in the strain L40 (ref. 22). Activation of the LexA operator-HIS3 reporter was assayed on medium lacking histidine with increasing concentrations of 3 -aminotriazole.

Transfection, immunoprecipitation, immunoblot and metabolic labelling. For Smad2/Smad4 homo- or hetero-complex analysis, COS cells were transiently transfected with the indicated constructs and stimulated with 200 pM TGF- $\beta 1$ for $1 \mathrm{~h}$. Cells were lysed in TNE buffer ${ }^{3}$, immunoprecipitated with anti-Flag M2 monoclonal antibody (IBI; Eastman Kodak), and interacting proteins detected by immunoblotting with the anti-HA monoclonal antibody 12CA5 (Boehringer Mannheim) as described ${ }^{3}$. Anti-SMAD rabbit polyclonal antibody was raised against full-length Smadl. To study the interaction between the $\mathrm{N}$ and $\mathrm{C}$ domains of Smad4 or Smad2, transiently transfected COS cells were lysed in LSLD buffer (50 mM HEPES, pH 7.4, $50 \mathrm{mM} \mathrm{NaCl}$, $0.1 \%$ Tween $20,10 \%$ glycerol, $1 \mathrm{mM}$ DTT) containing protease and phosphatase inhibitors. Immunopreciptiaiton and immunoblotting were done as described. COS or R-1B/L17 cells transfected with the indicated constructs were labelled with ${ }^{35} \mathrm{~S}$-methionine or ${ }^{32} \mathrm{P}$-orthophosphate and visualized by electrophoresis and autoradiography ${ }^{23}$.

In vitro binding. The Smad $2 \mathrm{~N}$ domain (amino acids 1-184) fused to GST and the Smad2 C domain (amino acids 248-467) protein were expressed in Escherichia coli and partially purified by column chromatography. GST fusion proteins were conjugated to glutathione-Sepharose beads (Pharmacia) and incubated with Smad2 C domain protein. Smad2 C domain protein was detected by western blotting using anti-Smad antibody.

Functional assays. For the animal cap assay, RNA ( $10 \mathrm{nl}, 2 \mathrm{ng})$ was introduced in the animal pole of two-cell Xenopus embryos. Animal caps were explanted at the blastula stage and cultured to the tadpole stage. Total RNA from the explants and control sibling embryos was extracted and was amplified with reverse transcription by using muscle actin and $E F-1 \alpha$ primers $^{24}$. In the MDAMB468 cell experiments, the amount of transfected plasmids was adjusted to render the TGF- $\beta$ response dependent on both Smad 2 and Smad4. Luciferase and growth inhibition were assayed as described ${ }^{3}$.

Received 24 March; accepted 6 May 1997.

1. Hahn, S. A. et al. DPC4, a candidate tumor suppressor gene at human chromosome 18q21.1. Science 271, 350-353 (1996)

2. Eppert, K. et al. MADR2 maps to $18 \mathrm{q} 21$ and encodes a TGF- $\beta$-regulated MAD-related protein that is functionally mutated in colorectal carcinoma. Cell 86, 543-552 (1996).

3. Lagna, G., Hata, A., Hemmati-Brivanlou, A. \& Massagué, J. Partnership between DPC4 and SMAD proteins in TGF- $\beta$ signalling pathways. Nature 383, 832-836 (1996).

4. Liu, F. et al. A human Mad protein acting as a BMP-regulated transcriptional activator. Nature $\mathbf{3 8 1}$ 620-623 (1996)

5. Baker, J. \& Harland, R. M. A novel mesoderm inducer, mMadr-2, functions in the activin signal transduction pathway. Genes Dev. 10, 1880-1889 (1996).

6. Massagué, J., Hata, A. \& Liu, F. TGF- $\beta$ signalling through the Smad pathway. Trends Cell Biol. 7, $187-$ 192 (1997).

7. Zhang, Y., Feng, X.-H., Wu, R.-Y. \& Derynck, R. Receptor-associated Mad homologues synergize as effectors of the TGF- $\beta$ response. Nature 383, 168-172 (1996).

8. Hoodless, P. A. et al. MADR1, a MAD-related protein that functions in BMP2 signaling pathways. Cell 85, 489-500 (1996)

9. Macías-Silva, M. et al. MADR2 is a substrate of the TGFß receptor and phosphorylation is required for nuclear accumulation and signaling. Cell 87, 1215-1224 (1996)

10. Kretzschmar, M., Liu, F., Hata, A., Doody, J. \& Massagué, J. The TGF- $\beta$ family mediator Smad1 is phosphorylated directly and activated functionally by the BMP receptor kinase. Genes Dev. 11, 984995 (1997)

11. Wu, R.-Y., Zhang, Y., Feng, X.-H. \& Derynck, R. Heteromeric and homomeric interactions correlated with signaling activity and functional cooperativity of Smad3 and Smad4/DPC4. Mol. Cell. Biol. 17, 2521-2528 (1997)
12. Shi, Y., Hata, A., Lo, R. S., Massagué, J. \& Pavletich, N. P. A structural basis for mutational inactivation of the tumour suppressor Smad4. Nature 388, 87-93 (1997).

13. Cárcamo, J. et al. Type I receptors specify growth inhibitory and transcriptional responses to TGF- $\beta$ and activin. Mol. Cell. Biol. 14, 3810-3821 (1994).

14. Schutte, M. et al. DPC4 gene in various tumor types. Cancer Res. 56, 2527-2530 (1996).

15. Kim, S. K. et al. DPC4, a candidate tumor suppressor gene, is altered infrequently in head and neck squamous cell carcinoma. Cancer Res. 56, 2519-2521 (1996).

16. Nagatake, M. et al. Somatic in vivo alterations of the DPC4 gene at 18q21 in human lung cancers. Cancer Res. 56, 2718-2720 (1996).

17. Barrett, M. T., Schutte, M., Kern, S. E. \& Reid, B. J. Allelic loss and mutational analysis of the DPC4 gene in esophageal adenocarcinoma. Cancer Res. 56, 4351-4353 (1996).

18. Riggins, G. J. et al. Mad-related genes in the human. Nature Genet. 13, 347-349 (1996).

19. Uchida, K. et al. Somatic in vivo alternations of the JV18-1 gene at $18 \mathrm{q} 21$ in human lung cancers. Cancer Res. 56, 5583-5585 (1996).

20. Graff, J. M., Bansal, A. \& Melton, D. A. Xenopus Mad proteins transduce distinct subsets of signals for the TGF $\beta$ superfamily. Cell 85, 479-487 (1996).

21. Bartel, P. L., Chien, C.-T., Sternglanz, R. \& Fields, S. in Cellular Interactions in Development: A Practical Approach (ed. Hartley, D. A.) 153 (Oxford University Press, Oxford, 1993).

22. Voitek, A. B., Hollenberg, S. M. \& Cooper, J. A. Mammalian Ras interacts directly with the serine/ threonine kinase Raf. Cell 74, 205-214 (1993).

23. Wrana, J. L., Attisano, L., Wieser, R., Ventura, F. \& Massagué, J. Mechanism of activation of the TGF- $\beta$ receptor. Nature 370, 341-347 (1994).

24. Hemmati-Brivanlou, A. \& Melton, D. A. Inhibition of activin receptor signalling promotes neuralization in Xenopus. Cell 77, 273-281 (1994).

Acknowledgements. We thank Y. Shi for recombinant Smad2 proteins, and I. Reynisdóttir, J. Doody and S. Lee for advice and technical assistance. G.L. thanks A. Hemmati-Brivanlou for support and advice. This work was supported by NIH Breast Spore and Cancer Center grants. D.W. is the recipient of a postdoctoral fellowship from the Human Frontier Science Program. A.H. is a research associate and J.M. an investigator of the Howard Hughes Medical Institute.

Correspondence and requests for materials should be addressed to J.M. (e-mail: j-massague@ski.mskcc. org).

\section{A structural basis for mutational inactivation of the tumour suppressor Smad4}

\section{Yigong Shi, Akiko Hata*, Roger S. Lo*, Joan Massagué \& Nikola P. Pavletich}

Cellular Biochemistry and Biophysics Program, ${ }^{*}$ Cell Biology Program and the Howard Hughes Medical Institute, Memorial Sloan-Kettering Cancer Center, New York, New York 10021, USA

The Smad4/DPC4 tumour suppressor ${ }^{1}$ is inactivated in nearly half of pancreatic carcinomas ${ }^{2}$ and to a lesser extent in a variety of other cancers ${ }^{2-4}$. Smad4/DPC4, and the related tumour suppressor Smad2, belong to the SMAD family of proteins that mediate signalling by the TGF- $\beta$ /activin/BMP-2/4 cytokine superfamily from receptor Ser/Thr protein kinases at the cell surface to the nucleus $^{5-7}$. SMAD proteins, which are phosphorylated by the activated receptor, propagate the signal, in part, through homoand hetero-oligomeric interactions ${ }^{8-13}$. Smad4/DPC4 plays a central role as it is the shared hetero-oligomerization partner of the other SMADs. The conserved carboxy-terminal domains of SMADs are sufficient for inducing most of the ligand-specific effects, and are the primary targets of tumorigenic inactivation. We now describe the crystal structure of the C-terminal domain (CTD) of the Smad4/DPC4 tumour suppressor, determined at $2.5 \AA$ resolution. The structure reveals that the Smad4/DPC4 CTD forms a crystallographic trimer through a conserved proteinprotein interface, to which the majority of the tumour-derived missense mutations map. These mutations disrupt homooligomerization in vitro and in vivo, indicating that the trimeric assembly of the Smad4/DPC4 CTD is critical for signalling and is disrupted by tumorigenic mutations.

The conserved C-terminal domain can mediate many of the biological effects of SMAD proteins, and the conserved $\mathrm{N}$-terminal domain can negatively regulate the SMAD activity ${ }^{14,15}$. When overexpressed in a Smad4/DPC $4^{-/-}$cell line, the Smad4/DPC4 CTD can activate the transcription of TGF- $\beta$ responsive genes and result in 